a stage in which a slow production of lactic acid and phosphoric acid in equivalent amounts takes place. The hexosephosphoric acid formed is approximately equivalent in amount to the amount of lactic acid produced.

This state of affairs presents, as will be seen, the most complete analogy to what occurs in alcoholic fermentation, with the difference that in one case the product is lactic acid and in the other alcohol and carbon dioxide. There is the same great acceleration in the rate of the reaction, accompanied by the accumulation of hexosephosphoric acid, the same drop in the rate when the free phosphoric acid is exhausted, and the same succeeding slow rate of change. As in the case of alcoholic fermentation, fructose reacts much more rapidly than glucose. There seems to be no doubt that the same fundamental change is in progress in the two cases.

Meyerhof believes that the hexosephosphoric acid produced is converted whilst in statu nascendi into the final products-lactic acid or alcohol and carbon dioxide (or some precursor of these) and phosphoric acid.

As, however, the rate of esterification is greater than that of decomposition, some of the phosphoric ester becomes stabilised in the less reactive form in which it can be isolated.
In the intact yeast cell and the natural muscle there is no accumulation of hexosephosphoric acid, " probably because, as the result of an accurate coordination, the whole of the labile ester produced is fermented, and not only about one-half of it, as in the extracts.'

This explanation scarcely accounts for the approximate equivalence between the amounts of hexose decomposed and converted into the stable ester, and there is doubtless more yet to be learned on this point.

The striking similarity established by Meyerhof between the changes of carbohydrates in muscle and in the yeast cell is seen to be much closer than has been believed. The remarkable phenomena accompanying alcoholic fermentation are now duplicated in the case of lactic acid production, and it may reasonably be expected that most of the fermentative decompositions of the sugars will be found to be initiated in a similar manner.

It is a great achievement to have pushed the analysis of the production of lactic acid so far, and further results of this line of investigation will be awaited with the greatest interest.

Arthur Harden.

\title{
A Royal Collection of Scientific Instruments.
}

$A \mathrm{~N}$ interesting historical document is described by Mr. Robert S. Whipple in "An Old Catalogue and what it tells us of the Scientific Instruments and Curios collected by Queen Charlotte and King George III." (Reprinted from the Proceedings of the Optical Convention, r926. Part 2.) The catalogue, which has been preserved at the Kew Observatory, was prepared in 1770 or a few years later. A reproduction of the first page of the catalogue is given, the complete catalogue (319 entries), and a "Catalogue of Presents by Sundry Persons" (77 entries) being printed as an appendix to the paper.

Whilst the first catalogue is confined wholly to scientific apparatus and instruments, a large proportion being of the educational or teaching type, the 'presents' are mainly of the 'natural history' type, including such objects as ' a dried cat,' ' a lizzard in spirits,' ' fosils from Virginia,' ' two Batavia rats,' 'two spiders from Bardadoes,' etc. In the latter list the names of the distinguished donors are given.

Before describing the contents of the collection, Mr. Whipple gives an account of the foundation of the King's Observatory at Kew for the purpose of observing the transit of Venus in I769. Some of the instruments included in the catalogue were used in the observations, and the original notes (preserved in the Library of King's College, London) by Dr. Demainbray recording the observations are published, it is believed for the first time. King George III. acted as an assistant during the observations. Queen Charlotte and the Princes Ernest and George of Mecklenburg-Strelitz were present, and others taking part were Col. Desaguliers, Rev. Geo. Wollaston, Stephen Rigaud, Justin and Benjamin Vulliamy, Jeremiah Sisson, and John Cuff.

Full details are given of the instruments used. and of the observations made. It is interesting to read that " His Majesty the King who made his Observation with a Short's Reflecting Telescope, magnifying Diameters r7o Times, was the first who saw the Penumbra of Venus touching the Edge of the Sun's Disk." There is.a note afterwards to the effect that " his Majesty thinks he saw it before he gave his Signal to Doctor Demainbray, who attended at the Regulator. And that Mr. Sisson (fearful of giving a false Alarum) waited an Instant before he caused Mr. Cuff to ring the Bell."

$$
\text { NO. 298I, VOL. II 8] }
$$

The collection of instruments and apparatus as specified in the Queen's Catalogue, with other objects afterwards acquired, remained as a national collection in the Kew Observatory until $x 84 \mathrm{x}$, when the Government decided to discontinue the maintenance of the Observatory. Mr. Whipple gives in detail the circumstances leading to this decision, and the consequent distribution of the collection to various institutions and individuals.

Some of the instruments and apparatus which went to King's College, with a request that "they should be preserved together as a whole" (forming the George III. Museum), are described and illustrated. The present locations of some of these, as well as of instruments which went to other institutions, are given.

Of the larger instruments included in the Catalogue, perhaps the best known to the general public are the large eight-feet mural quadrant by Jeremiah Sisson, and the observatory clock by Benjamin Vulliamy. These have been exhibited for many years in the Science Museum at South Kensington. Of the transit instrument, which went to Armagh Observatory, only the object-glass and the mahogany stand for lifting and reversing the telescope are still in existence, the object-glass being used at present for testing planes. The lens and some parts of the five-feet " astronomical sector in dome," as well as the six-inch telescope (probably that used by the King in I769) made by Short in $\mathbf{I} 745$, are still preserved at Armagh.

Mr. Whipple gives interesting evidence of the circumstances in which the valuable old microscopes were acquired by the late Sir Frank Crisp from the George III. Museum. The King's College authorities, though aware of the great historical value of the instruments, agreed to the transference only after much pressure, and "having been given the assurance that the Crisp collection was destined for the nation." Mr. Whipple adds: "The fact that the assurance was not fulfilled illustrates the importance of entrusting instruments or other objects of historical interest to a National Museum."

Since this interesting and valuable paper was read at the Optical Convention last April, the George III. collection, which was then still at King's College, has been transferred on loan to the Science Museum. 